\title{
Concerns on the Emerging Research of SARS-CoV-2 on Felines: Could They be Significant Hosts/Reservoirs?
}

\author{
D. Katterine Bonilla-Aldana ${ }^{1,2}$ (D) Julian Ruiz-Saenz ${ }^{3}$ D, Marlen Martinez- \\ Gutierrez $^{3}(\mathbb{D})$, Ruchi Tiwari ${ }^{4}\left(\mathbb{D}\right.$, Kuldeep Dhama ${ }^{5}$ (D) Javier A. Jaimes ${ }^{6}{ }^{(D)}$, and \\ Alfonso J. Rodriguez-Morales ${ }^{2,7 *}$ (i)
}

\begin{abstract}
${ }^{1}$ Incubator in Zoonosis (SIZOO), Biodiversity and Ecosystem Conservation Research Group (BIOECOS), Fundacion Universitaria Autonoma de las Americas, Sede Pereira, Pereira, Risaralda, Colombia. ${ }^{2}$ Public Health and Infection Research Group and Incubator, Faculty of Health Sciences, Universidad Tecnologica de Pereira, Pereira, Risaralda, Colombia. ${ }^{3}$ Grupo de Investigacion en Ciencias Animales, Universidad Cooperativa de Colombia, Bucaramanga, Santander, Colombia. ${ }^{4}$ Department of Veterinary Microbiology and Immunology, College of Veterinary Sciences, Uttar Pradesh Pandit Deen Dayal Upadhyaya Pashu Chikitsa Vigyan Vishwavidyalaya Evam Go Anusandhan Sansthan (DUVASU), Mathura, India -281001, India. ${ }^{5}$ Division of Pathology, ICAR-Indian Veterinary Research Institute, Izatnagar, Bareilly- 243 122, Uttar Pradesh, India. ${ }^{6}$ Department of Microbiology \& Immunology, College of Veterinary Medicine, Cornell University, Ithaca, NY 14853, USA. ${ }^{7}$ Grupo de Investigacion Biomedicina, Faculty of Medicine, Fundacion Universitaria Autonoma de las Americas, Pereira, Risaralda, Colombia.
\end{abstract}

\section{Abstract}

With the growing evidence of cases and studies showing natural and experimental infection due to SARS-CoV-2 in felines, including cats, lion, and tigers, there is also an increasing concern about its susceptibility and their role in urban cycles of SARS-CoV-2 transmission, initially from humans-toanimals, but with uncertainty about reverse transmission. In this review, we addressed the evidence around this situation.

Keywords: SARS-CoV-2, COVID-19, Animals, Feline, Anthropozoonotic, Pandemic

\begin{abstract}
*Correspondence: ajrodriguezmmd@gmail.com
\end{abstract}
(Received: April 20, 2020; accepted: April 28, 2020)

Citation: Bonilla-Aldana DK, Ruiz-Saenz J, Martinez-Gutierrez M, et al. Concerns on the Emerging Research of SARS-CoV-2 on Felines: Could They be significant Hosts/Reservoirs?. J Pure Appl Microbiol. 2020;14(suppl 1):703-708. doi: 10.22207/JPAM.14. SPL1.04

(C) The Author(s) 2020. Open Access. This article is distributed under the terms of the Creative Commons Attribution 4.0 International License which permits unrestricted use, sharing, distribution, and reproduction in any medium, provided you give appropriate credit to the original author(s) and the source, provide a link to the Creative Commons license, and indicate if changes were made. 


\section{INTRODUCTION}

Coronaviruses (CoV) are a group of widely known enveloped single-stranded, nonsegmented RNA viruses. These belong to the Orthocoronavirinae subfamily, Coronaviridae family, in the order Nidovirales, and they are classified into four genera: Alpha, Beta, Gamma, and Deltacoronavirus ${ }^{1}$. CoVs are worldwide distributed pathogens ${ }^{2}$, can infect both animals and humans, and transmission between species is a common feature of these viruses ${ }^{3}$. Currently, one $\mathrm{CoV}$ is causing a pandemic ${ }^{4}$.

CoVs are commonly circulating in animal and human populations around the world, as is the case of the human CoVs NL63, 229E, OC43, and HKU1 ${ }^{5}$. These viruses mainly cause minor respiratory problems and are not a matter of concern, as long as they do not infect immunocompromised a patient, where infection may lead to fatal outcomes ${ }^{6}$. However, preoccupation comes from CoVs may spill from natural hosts, infect intermediate hosts, and finally reach human populations ${ }^{7}$, like the Severe Acute Respiratory Syndrome coronavirus 2 (SARS-CoV-2) caused $^{8}$.

Animal origins

The SARS-CoV emerged in $2002^{9}$. The SARS-CoV transmission was initially linked to the Himalayan palm civet (Paguna larvata) ${ }^{10}$. However, there are other animal species involved. Animals such as bats but also Chinese ferret-badgers (Melogale moschata) and raccoondogs (Nyctereutes procyonoides) ${ }^{11,12}$ have been involved. A decade later, other CoVs caused preoccupation when the epidemiological links of the Middle East Respiratory Syndrome coronavirus (MERS-CoV) between human and camel cases were also confirmed ${ }^{13,14}$, indicating animal-human transmission was a recurrent event for CoVs. More recently, during the last month of 2019, a new CoV emerged in Wuhan City in Hubei Province of mainland China, causing a mostly mild respiratory disease, with fatal consequences for elders and people with co-morbidities ${ }^{15,16}$. The outbreak has been associated to a wet market where more than 120 live animal species were found, which people are in contact with or consume different animals, primarily fish and sea food ${ }^{4,17-20}$. The virus was initially named 2019-nCoV, but the name was later changed to SARS-CoV-2, and the disease it caused was named Coronavirus Disease 2019 (COVID-19) $^{21}$. While the origin of the virus has been related to SARS-like CoVs circulating in bat populations, an intermediate host between bats and humans is yet to be determined ${ }^{22}$. Multiple phylogenetic studies have also served as an approach for hypothesis in the animal origins of SARS-CoV- $2^{15,16}$. At the moment, multiple animals are a matter of investigation as possible susceptible hosts for SARS-CoV- $2^{23}$.

SARS-CoV-2 Infection in Domestic Animals and Felines

Throughout SARS-CoV-2 studies, there have been concerns about infection in animals, mainly domestic, and there have been sporadic reports in dogs $^{24}$ and, subsequently, feline case in Hong Kong ${ }^{25}$. That domestic cat was the property of an adult man hospitalized due to SARS-CoV-2 infection and was quarantined on March 30, 2020. After veterinary examination, nasal, oral, and rectal swabs were collected when the cat was admitted to the quarantine center. All samples tested positive for RT-qPCR for SARS-CoV- $2^{25}$. Another domestic cat in Belgium, living with a human diagnosed with SARS-CoV-2 infection have also been reported to be infected with SARS-CoV-2 ${ }^{26}$. Additionally, recently a tiger tests positive for SARS-CoV-2 at the Bronx Zoo in New York City, while six others are exhibiting signs consistent with the SARS-CoV-2 infection ${ }^{27}$.

In addition to the reports mentioned above, major international concern has been reached over new data generated in two studies about SARS-CoV-2 in cats $^{28}$. First, it was a study conducted at five cats to investigate the susceptibility of them and other animals in close contact with humans with SARS-CoV-2 infection. They found canines, pigs, chickens, and ducks were not susceptible to the virus, while ferrets and cats were. Interestingly, the study also suggested that transmission between infected and non-infected cats as possible, as one naïve cat became positive after having close contact with a previously infected cat. In the study, cats were intranasally inoculated with $10^{5} \mathrm{PFU}$ of $\mathrm{CTan}-\mathrm{H}$, an isolated virus from a human (SARS-CoV-2/CTan/ human/2020/Wuhan) $)^{23}$. After six days, two cats were euthanized, and the viral RNA was detected in the nasal turbinates, soft palates, and tonsils of both animals, in the trachea of one animal, and 
the small intestine of the other. However, viral RNA was not detected in the lungs. A similar result was obtained in the cats that were euthanized after 12 days. Antibodies against SARS-CoV-2 were detected in all three virus-inoculated subadult cats and one exposed cat by use of an ELISA and neutralization assay, although without relevant clinical findings ${ }^{23}$. According to the authors, the cats used in the study were outbred and were also highly susceptible to SARS-CoV-2, which replicated and transmitted efficiently to naïve cats ${ }^{23}$.

The other study focused mainly on detecting specific serum antibodies in cats infected with SARS-CoV- ${ }^{29}$. The authors assessed a cohort of serum samples collected from cats in Wuhan, 102 of them obtained after the beginning of the COVID-19 emergency, and 39 before the start of this outbreak. 15 out of 102 (14.7\%) serum samples collected after the beginning of the outbreak were positive for antibodies against the receptor-binding domain (RBD) of SARSCoV-2 by indirect enzyme-linked immunosorbent assay (ELISA). Among the positive samples, 11 had SARS-CoV-2 neutralizing antibodies with a titer ranging from $1 / 20$ to $1 / 1080$. The 39 serum samples collected before the outbreak's onset were negative ${ }^{29}$. Additionally, no serological crossreactivity was detected between the SARS-CoV-2 and type I or II of feline infectious peritonitis virus (FIPV). According to their results, the authors suggested that the studied cat population in Wuhan was infected with SARS-CoV-2 after the start of the outbreak ${ }^{29}$.

The U. S. Department of Agriculture (USDA), U.S. Centers for Disease Control and Prevention (CDC), National Veterinary Services Laboratories and Wildlife Conservation Society (WCS) have confirmed that big cat Nadia, as a fouryear-old Malayan tiger was found positive for SARSCoV-2 and thereby is the first animal acquiring the SARS-CoV-2 infection through human workers at the Bronx Zoo, New York, United States ${ }^{30}$. Several other lions and tigers inside the Bronx Zoo also presented clinical signs of respiratory distress as claimed by USDA but have not been tested to date by laboratory investigations ${ }^{31}$. The World Organization for Animal Health (OIE) has advised as SARS-CoV-2 is widely prevalent in the human population, hence the risk of its transmission to jointly residing pets, domestic animals, and zoo animals cannot be ignored. This probability was confirmed after getting positive reports of SARS-CoV-2 from dogs, cats and tigers, recently from different countries ${ }^{32}$. The U.S. CDC has recommended persons who are asymptomatic but suspected for SARS-CoV-2 or those who are infected should avoid proximity to susceptible animals ${ }^{33}$. More recently in New York also, two cats reportedly tested positive for SARS-CoV-2 in New York. Both had owners who were COVID-19 positive, and both animals were reportedly exhibiting respiratory signs. Additional samples are reportedly being sent to the National Veterinary Services Laboratories for confirmation ${ }^{34}$.

The present results cannot be separated from the results previously obtained during the beginning of the century during the first SARS-CoV outbreak. As is well known, SARS-CoV-2 is a virus highly related to SARS-CoV, causing the pandemic in late 2002 and that by mid-2003 was distributed to 29 countries, leaving an estimated number of 8,098 people $2002^{9}$. During this pandemic event, the presence of SARS-CoV was also reported in cats in places where positive symptomatic humans lived, some of these animals with signs of disease ${ }^{35}$. As in the present outbreak, studies of experimental infection in cats and ferrets demonstrated the high infectious capacity of SARS-CoV in these species, evidencing the spread of infection to multiple organs and viral excretion with the ability to infect susceptible animals in close contact ${ }^{36}$. From a pathological point of view, it was shown that cats could carry the disease subclinically and present lesions similar to those found in humans infected with this virus, characterized by the presence of diffuse alveolar damage associated with the presence of SARS- CoV and, especially in cats, the presence of tracheobronchoadenitis ${ }^{37}$.

Supporting the in vivo experimental studies, recent in silico analysis of the interaction between the SARS-CoV- 2 spike protein and the cellular receptor ADE2 in various animal species, suggests that the majority of wild and domestic cats are susceptible to SARS-CoV-2. However, the domestic cat would be more likely to act as a reservoir or intermediary animal, considering the interaction between these cellular and viral proteins is very similar to observed in humans ${ }^{38}$. Feline coronaviruses

Cats can naturally become infected with 
other Coronaviruses, such as feline coronavirus $(\mathrm{FCoV})^{39}$, which belongs to the Alphacoronavirus genus, along with canine coronavirus (CCoV) and transmissible gastroenteritis virus (TEGV) of pigs. Alphacoronavirus species ${ }^{40}$. The FCoV is known to occur in two pathotypes: the enteric coronavirus that invades the digestive tract - FECV (Feline Enteric Coronavirus Virus), and the virus responsible for feline infectious peritonitis (FIP) is known as FIPV (Feline Infectious Peritonitis Virus) ${ }^{41}$. Feline and canine coronaviruses usually do not infect human beings and mostly affect dogs and cats. However, the most recent report of one big cat at the zoo found positive for SARS-CoV-2, the emerging novel coronavirus that was initially claimed to affect man only but not the animals ${ }^{33}$.

The FECV virus is responsible for the infection of cats' digestive epithelial cells. This infection is mainly asymptomatic and remains undetected or causes mild and transient diarrhea ${ }^{42}$. The virus is highly contagious and is believed to transmit horizontally through the fecaloral route. Kittens are usually infected with FECV at an early age in the litter, most likely through viruses in the mother's feces. Since persistently infected cats shed the virus in their feces for prolonged periods, they play a central role in the spread and maintenance of FECV in populations. This infection can be diagnosed by smearing cells from the anal swabs and by detecting the virus's RNA using the Polymerase Chain Reaction ${ }^{43}$. FIP is a fatal disease, being common in young cats (under three years old and especially two years old). The virus is not infectious, but it has been suggested to arise from the FECV mutation in a small percentage of infected cats and then causes FIPV disease ${ }^{44,45}$. Mutations in the accessory genes and the FCoV S gene have been associated with the development of FIP. FIPV replicates efficiently in monocytes and macrophages and induces systemic diseases. The disease is characterized by fibrinous and granulomatous serositis, serous effusion rich in proteins in body cavities, and granulomatous lesions (pyogranulomas) ${ }^{46}$. Clinical signs of infected cats include lethargy, anorexia, weight loss, or inability to gain weight, stunted growth in younger cats $^{44}$.

The definitive diagnosis of FIPV is based on the histopathological examination of the tissues, generally with the detection of the virus within the lesions by immunohistochemistry (IHC) for the FCoV antigen. Immunostaining of the FCoV antigen in secretion samples is also an option in cases with a secretion biochemical and cytological characteristics compatible with FIP. There are currently no treatments available for FIPV, although some novel treatments, including protease inhibitors, are promising ${ }^{47}$.

For many years, the origin of FIPV was unclear and was discussed in quite a controversial way. In the first investigations, FECV and FIPV were considered different virus species. In subsequent studies, FECV and FIPV were proposed to be closely related to viruses with distinct virulence properties. In recent years, many aspects of FCoV biology have been studied, providing an attractive new look at the pathogenesis of FIP; however, several important questions remain to be answered ${ }^{48}$.

Here, we have discussed the principal characteristics of two different infectious agents: SARS-CoV-2 and FCoV. While the latter is a wellknown infectious agent of felids, the former appears to arise as a new threat to these animals. The reasons behind this phenomenon could be related to the relative similarity between the human and the angiotensin-converting enzyme 2 (ACE2), which is used by the SARS-CoV-2 to colonize the cells ${ }^{49}$. However, how the SARS-CoV-2 could infect cats, is a concerning aspect yet of being elucidated. Indeed, the worrisome findings of recent case reports and studies, move toward more research and careful management of the interaction between humans and cats in the context of COVID-19.

\section{CONCLUSIONS}

Definitive conclusions in this matter cannot be generated until further investigations are performed. Surveillance for SARS-CoV- 2 in cats should be considered as an adjunct to a better understanding of COVID-19's epidemiology and dynamic in humans and animals. As the current reports have shown that cats can be infected as a consequence of close contact with SARS-CoV-2 infected people, further considerations must be taken to reduce the risk of infection to cats. The available studies have not addressed the study of the human-cat transmission of SARS-CoV-2. Therefore, the question about the role of cats 
in the transmission of SARS-CoV-2 to humans is still unanswered. While this topic may become a matter of concern and debate until more research data is available, cats must not be considered part of the transmission cycle of SARS-CoV-2.

\section{ACKNOWLEDGMENTS}

None.

\section{CONFLICT OF INTEREST}

The listed author(s) declare no conflict of interest in any capacity, including competing or financial.

\section{AUTHORS' CONTRIBUTION}

AJRM conceived the idea of the MiniReview. DKBA perform a review of the literature on the topic related; all authors read the cited literature; AJRM developed the first draft of the manuscript; all authors contributed consequently with newer versions; all authors approved the final submitted version.

\section{FUNDING}

None.

\section{ETHICS STATEMENT}

This article does not contain any studies with human participants or animals performed by any of the authors.

\section{AVAILABILITY OF DATA \\ Not applicable.}

\section{REFERENCES}

1. Cui J, Li F, Shi ZL. Origin and evolution of pathogenic coronaviruses. Nat Rev Microbiol. 2019;17:181-92. https://doi.org/10.1038/s41579-018-0118-9

2. Guarner J. Three Emerging Coronaviruses in Two Decades. Am J Clin Pathol. 2020;153:420-1. https:// doi.org/10.1093/ajcp/aqaa029

3. Jaimes JA, Andre NM, Millet JK, Whittaker GR. Structural modeling of 2019-novel coronavirus (nCoV) spike protein reveals a proteolytically-sensitive activation loop as a distinguishing feature compared to SARS-CoV and related SARS-like coronaviruses. bioRxiv. https://doi.org/10.1101/2020.02.10.942185

4. Li Q, Guan X, Wu P, et al. Early Transmission Dynamics in Wuhan, China, of Novel Coronavirus-Infected Pneumonia. NEng/J Med. 2020;382:1199-207. https:// doi.org/10.1056/NEJMoa2001316

5. Villamil-Gomez WE, Sanchez A, Gelis L, et al. Fatal human coronavirus 229E (HCoV-229E) and RSV-
Related pneumonia in an AIDS patient from Colombia. Travel Med Infect Dis. 2020:101573. https://doi. org/10.1016/j.tmaid.2020.101573

6. Pene F, Merlat A, Vabret A, et al. Coronavirus 229E-related pneumonia in immunocompromised patients. Clin Infect Dis. 2003;37:929-32. https://doi. org $/ 10.1086 / 377612$

7. Rodriguez-Morales AJ, Bonilla-Aldana DK, BalbinRamon GJ, et al. History is repeating itself, a probable zoonotic spillover as a cause of an epidemic: the case of 2019 novel Coronavirus. Infez Med. 2020;28:3-5.

8. Bonilla-Aldana DK, Villamil-Gomez WE, Rabaan AA, Rodriguez-Morales AJ. Una nueva zoonosis viral de preocupacion global: COVID-19, enfermedad por coronavirus 2019. Latreia. 2020;33:107-10.

9. Al-Tawfiq JA, Zumla A, Memish ZA. Travel implications of emerging coronaviruses: SARS and MERS-CoV. Travel Med Infect Dis. 2014;12:422-8. https://doi. org/10.1016/j.tmaid.2014.06.007

10. Guan $\mathrm{Y}$, Zheng BJ, He YQ, et al. Isolation and characterization of viruses related to the SARS coronavirus from animals in southern China. Science. 2003;302:276-8. https://doi.org/10.1126/ science.1087139

11. Li W, Shi Z, Yu M, et al. Bats are natural reservoirs of SARS-like coronaviruses. Science. 2005;310:676-9. https://doi.org/10.1126/science.1118391

12. Wang LF, Eaton BT. Bats, civets and the emergence of SARS. Curr Top Microbiol Immunol. 2007;315:325-44. https://doi.org/10.1007/978-3-540-70962-6_13

13. Azhar El, El-Kafrawy SA, Farraj SA, et al. Evidence for camel-to-human transmission of MERS coronavirus. N Engl J Med. 2014;370:2499-505. https://doi. org/10.1056/NEJMoa1401505

14. Harcourt JL, Rudoler N, Tamin A, et al. The prevalence of Middle East respiratory syndrome coronavirus (MERS-CoV) antibodies in dromedary camels in Israel. Zoonoses Public Health. 2018;65:749-54. https://doi. org/10.1111/zph.12482

15. Li X, Song $Y$, Wong $G$, Cui J. Bat origin of a new human coronavirus: there and back again. Sci China Life Sci. 2020;63:461-2. https://doi.org/10.1007/s11427-020$1645-7$

16. Zhou P, Yang XL, Wang XG, et al. A pneumonia outbreak associated with a new coronavirus of probable bat origin. Nature. 2020;579:270-3. https://doi. org/10.1038/s41586-020-2012-7

17. Chan JF, Yuan S, Kok KH, et al. A familial cluster of pneumonia associated with the 2019 novel coronavirus indicating person-to-person transmission: a study of a family cluster. Lancet. 2020;395:514-23. https://doi.org/10.1016/S0140-6736(20)30154-9

18. Chen N, Zhou M, Dong X, et al. Epidemiological and clinical characteristics of 99 cases of 2019 novel coronavirus pneumonia in Wuhan, China: a descriptive study. Lancet. 2020;395:507-13. https:// doi.org/10.1016/S0140-6736(20)30211-7

19. Huang C, Wang Y, Li X, et al. Clinical features of patients infected with 2019 novel coronavirus in Wuhan, China. Lancet. 2020;395:497-506. https://doi.org/10.1016/ S0140-6736(20)30183-5 
20. Zhu N, Zhang D, Wang W, et al. A Novel Coronavirus from Patients with Pneumonia in China, 2019. N Engl J Med. 2020.

21. Ahmad T, Khan M, Haroon, et al. COVID-19: Zoonotic aspects. Travel Med Infect Dis. 2020:101607. https:// doi.org/10.1016/j.tmaid.2020.101607

22. Andersen KG, Rambaut A, Lipkin WI, Holmes EC, Garry RF. The proximal origin of SARS-CoV-2. Nature Medicine. 2020. https://doi.org/10.1038/s41591-0200820-9

23. Chen H. Susceptibility of ferrets, cats, dogs, and different domestic animals to SARS-coronavirus-2. bioRxiv. 2020: 2020.03.30.015347.

24. OIE. Follow-up report No. 3 (Final report). https://www. oie.int/wahis_2/public/wahid.php/Reviewreport/ Review?reportid=33762. 2020.

25. OIE. Immediate notification. https://www.oie. int/wahis_2/public/wahid.php/Reviewreport/ Review?page_refer=MapFull EventReport \&reportid= 33832. 2020.

26. AVMA. COVID-19: What veterinarians need to know https://www.avma.org/resources-tools/animalhealth-and-welfare/covid-19. 2020.

27. Daly N. Tiger tests positive for coronavirus at Bronx Zoo, first known case in the world. https://www. nationalgeographic.com/animals/2020/04/tigercoronavirus-covid19-positive-test-bronx-zoo/. 2020.

28. Mallapaty S. Coronavirus can infect cats - dogs, not so much. Nature. 2020. https://doi.org/10.1038/ d41586-020-00984-8

29. Zhang Q, Zhang $\mathrm{H}$, Huang $\mathrm{K}$, et al. SARS-CoV-2 neutralizing serum antibodies in cats: a serological investigation. bioRxiv. https://doi.org/10.1101/2020.04.01.021196

30. Law T, Leung H. A Tiger at the Bronx Zoo Has Tested Positive for Coronavirus. https://time.com/5815939/ tiger-bronx-zoo-positive-coronavirus/. 2020.

31. OIE. Information received on 06/04/2020 from Dr Mark Davidson, Associate Administrator, USDA-APHIS, United States Department of Agriculture, Washington, United States of America. https://www.oie.int/wahis_2/ public/wahid.php/Reviewreport/Review?page refer=MapFullEventReport\&reportid=33885. 2020.

32. OIE. Questions and Answers on the 2019 Coronavirus Disease (COVID-19). https://www.oie.int/en/ scientific-expertise/specific-information-andrecommendations/questions-and-answers-on2019novel-coronavirus/. 2020.

33. CDC. Coronavirus Disease 2019 (COVID-19). If You Have Animals. https://www.cdc.gov/coronavirus/2019ncov/daily-life-coping/animals.html. 2020.

34. ProMEDmail. PRO/AH/EDR> COVID-19 update (113): USA (NY) cat, animal, susp, RFI ProMEDmail. 2020; 2020: 20200418.7240811.

35. Wang $\mathrm{M}$, Jing $\mathrm{H}, \mathrm{Xu} \mathrm{H}$, et al. Surveillance on severe acute respiratory syndrome associated coronavirus in animals at a live animal market of Guangzhou in 2004. Zhonghua liu xing bing xue za zhi= Zhonghua liuxingbingxue zazhi. 2005;26:84-7.
36. Martina BE, Haagmans BL, Kuiken $\mathrm{T}$, et al. Virology: SARS virus infection of cats and ferrets. Nature. 2003;425:915. https://doi.org/10.1038/425915a

37. van den Brand JM, Haagmans BL, Leijten $L$, et al. Pathology of experimental SARS coronavirus infection in cats and ferrets. Vet Pathol. 2008;45:551-62. https:// doi.org/10.1354/vp.45-4-551

38. Wu C, Zheng M, Yang Y, et al. In Silico Analysis of Intermediate Hosts and Susceptible Animals of SARSCoV-2. ChemRxiv. 2020. https://doi.org/10.26434/ chemrxiv.12057996

39. Jaimes JA, Whittaker GR. Feline coronavirus: Insights into viral pathogenesis based on the spike protein structure and function. Virol. 2018;517:108-21. https://doi.org/10.1016/j.virol.2017.12.027

40. Jaimes JA, Millet JK, Stout AE, Andre NM, Whittaker GR. A Tale of Two Viruses: The Distinct Spike Glycoproteins of Feline Coronaviruses. Viruses. 2020;12. https://doi. org/10.3390/v12010083

41. Chang HW, Egberink HF, Halpin R, Spiro DJ, Rottier PJ. Spike protein fusion peptide and feline coronavirus virulence. Emerg Infect Dis. 2012;18:1089-95. https:// doi.org/10.3201/eid1807.120143

42. Desmarets LM, Vermeulen BL, Theuns $S$, et al. Experimental feline enteric coronavirus infection reveals an aberrant infection pattern and shedding of mutants with impaired infectivity in enterocyte cultures. Sci Rep. 2016; 6: 20022. https://doi. org/10.1038/srep20022

43. Stranieri A, Lauzi S, Giordano A, Paltrinieri S. Reverse transcriptase loop-mediated isothermal amplification for the detection of feline coronavirus. J Virol Methods. 2017;243:105-8. https://doi.org/10.1016/j. jviromet.2017.01.009

44. Felten S, Hartmann K. Diagnosis of Feline Infectious Peritonitis: A Review of the Current Literature. Viruses. 2019;11. https://doi.org/10.3390/v11111068

45. Licitra BN, Millet JK, Regan AD, et al. Mutation in spike protein cleavage site and pathogenesis of feline coronavirus. Emerg Infect Dis. 2013;19:1066-73. https://doi.org/10.3201/eid1907.121094

46. Kipar A, Meli ML. Feline infectious peritonitis: still an enigma? Vet Pathol. 2014;51:505-26. https://doi. org/10.1177/0300985814522077

47. Wang $\mathrm{H}$, Hirabayashi M, Chambers JK, Uchida K, Nakayama H. Immunohistochemical studies on meningoencephalitis in feline infectious peritonitis (FIP). J Vet Med Sci. 2018;80:1813-7. https://doi. org/10.1292/jvms.18-0406

48. Tekes G, Thiel HJ. Feline Coronaviruses: Pathogenesis of Feline Infectious Peritonitis. Adv Virus Res. 2016;96:193-218. https://doi.org/10.1016/ bs.aivir.2016.08.002

49. Wan Y, Shang J, Graham R, Baric RS, Li F. Receptor Recognition by the Novel Coronavirus from Wuhan: an Analysis Based on Decade-Long Structural Studies of SARS Coronavirus. J Virol. 2020;94. https://doi. org/10.1128/JVI.00127-20 